\title{
Diffuse cerebellar hypermetabolism: an early sign of leptomeningeal metastases
}

\author{
M. P. G. Broen ${ }^{1,2}$ (D) M. H. M. E. Anten ${ }^{1,2}$ - J. A. J. van der Pol ${ }^{3}$ \\ Received: 20 March 2021 / Accepted: 4 April 2021 / Published online: 17 April 2021 \\ (C) The Author(s) 2021
}

\begin{abstract}
A 20-year-old woman was referred to our center with a 3month history of progressive nausea, headache, and meningismus. She had surgery followed by proton-therapy three years earlier for a right-sided parasagittal atypical meningioma. Extensive blood and CSF examinations were done, but cultures remained negative and no infectious agents or malignant cells were identified. An ${ }^{18} \mathrm{~F}$-fluorodeoxyglucose (FDG)PET/CT showed intense hypermetabolism, exclusively involving the cerebellum, but no other abnormalities (Figure: A/C axial (a) and coronal (c) plane of ${ }^{18}$ F-FDG-PET/CT showing isolated diffuse hypermetabolism of the cerebellum; $\mathrm{B} / \mathrm{D}$ axial (b) and coronal (d) plane of ${ }^{18}$ F-FDG-PET fused with MR imaging, emphasizing the cortical location of the hypermetabolism). A repeated contrast-enhanced MRI showed new, intense leptomeningeal enhancement of the cerebellar
\end{abstract}

This article is part of the Topical Collection on Oncology - Brain

M. P. G. Broen

martijn.broen@mumc.nl

1 Department of Neurology, Maastricht University Medical Center+, Mailbox 5800, 6202 AZ Maastricht, The Netherlands

2 GROW- School for Oncology and Developmental Biology, Maastricht University, Maastricht, The Netherlands

3 Department of Radiology and Nuclear Medicine, Maastricht University Medical Center+, Maastricht, The Netherlands hemispheres, highly suspicious for leptomeningeal metastases. Leptomeningeal biopsy confirmed the diagnosis of leptomeningeal spread of the known meningioma, with rhabdoid transformation (WHO grade 3). Diffuse cerebellar cortical hypermetabolism on ${ }^{18} \mathrm{~F}$-FDG-PET/CT is a rare phenomenon reported in a few cases with paraneoplastic cerebellar degeneration $[1,2]$. But in this case, paraneoplastic cerebellar antibodies were all negative, in line with the lack of cerebellar signs on examination. Therefore, we postulate a differential diagnosis to this imaging sign, substantiated by pathological proof. Diffuse cerebellar cortical hypermetabolism on ${ }^{18} \mathrm{~F}$ FDG-PET/CT can be an early imaging marker for leptomeningeal metastases in solid tumors, appearing even before contrast enhancement on MR imaging. Recognizing this phenomenon may prevent delayed diagnosis and treatment. 

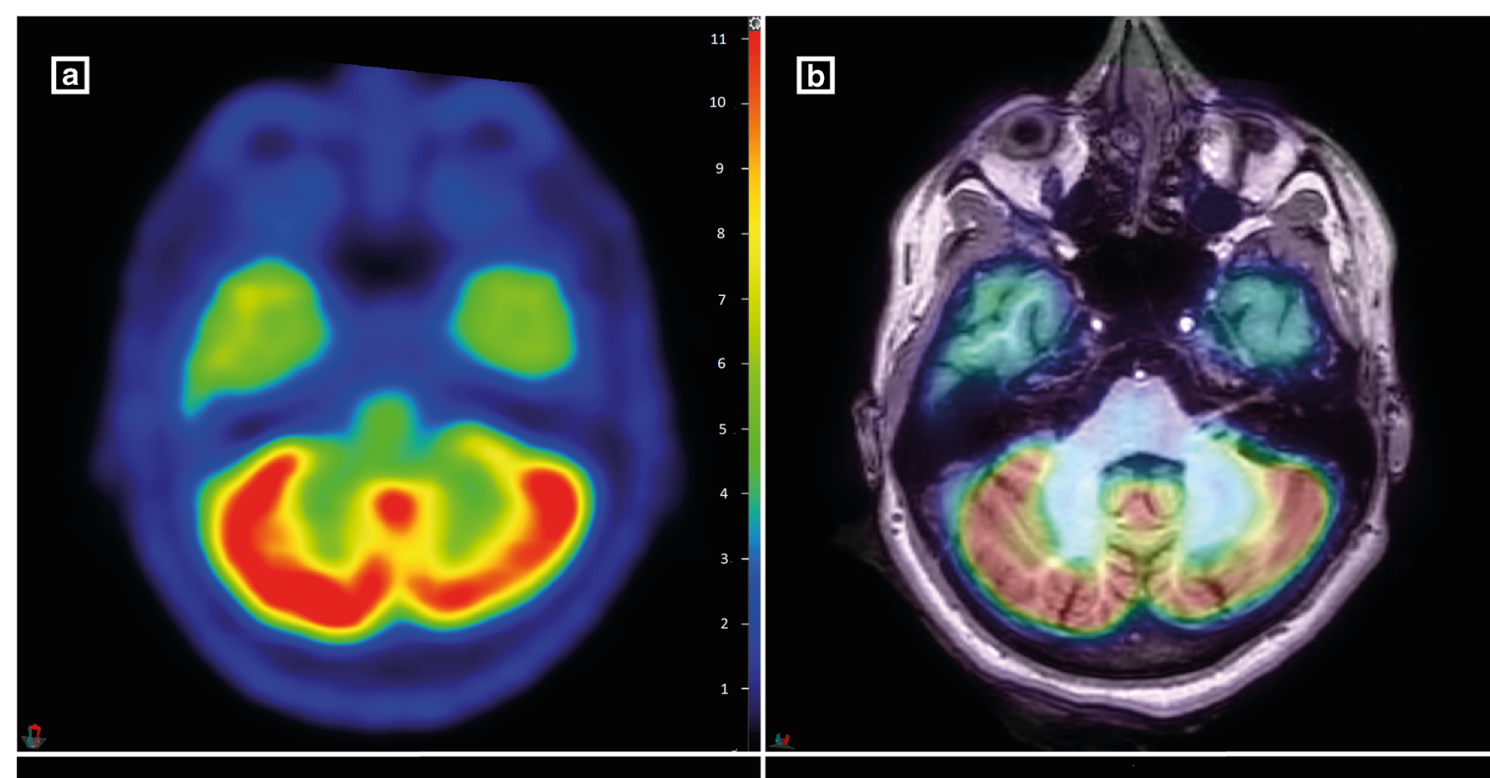

\section{四}
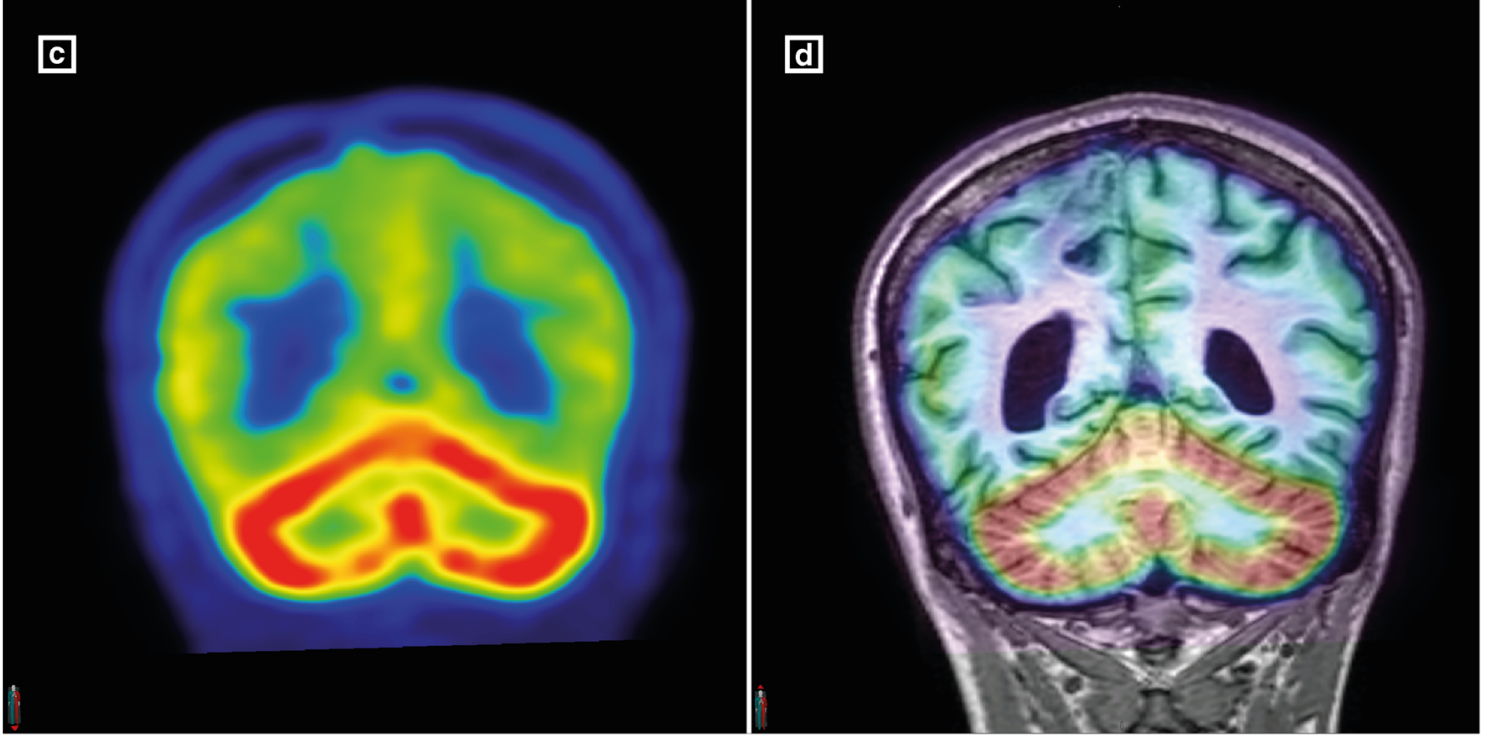

Author contribution MB: data collection and analysis, first draft, figure editing. MA: data collection, reviewing draft. JP: data collection, verifying data analysis, reviewing draft, and figure editing.

Data availability Not applicable

Code availability Not applicable

\section{Declarations}

Conflict of interest The authors declare no competing interests.

Open Access This article is licensed under a Creative Commons Attribution 4.0 International License, which permits use, sharing, adaptation, distribution and reproduction in any medium or format, as long as you give appropriate credit to the original author(s) and the source, provide a link to the Creative Commons licence, and indicate if changes were made. The images or other third party material in this article are included in the article's Creative Commons licence, unless indicated otherwise in a credit line to the material. If material is not included in the article's Creative Commons licence and your intended use is not permitted by statutory regulation or exceeds the permitted use, you will need to obtain permission directly from the copyright holder. To view a copy of this licence, visit http://creativecommons.org/licenses/by/4.0/.

\section{References}

1. Masangkay N, Basu S, Moghbel M, et al. Brain 18F-FDG-PET characteristics in patients with paraneoplastic neurological syndrome and its correlation with clinical and MRI findings. Nucl Med Commun. 2014;35:1038-46.

2. Choi KD, Kim JS, Park SH, et al. Cerebellar hypermetabolism in paraneoplastic cerebellar degeneration. J Neurol Neurosurg Psychiatry. 2006;77:525-8.

Publisher's note Springer Nature remains neutral with regard to jurisdictional claims in published maps and institutional affiliations. 